\title{
Emerging evidences for the opposite role of apolipoprotein C3 and apolipoprotein A5 in lipid metabolism and coronary artery disease
}

\author{
Wen Dai ${ }^{\dagger}$, Ziyu Zhang ${ }^{\dagger}$, Chun Yao and Shuiping Zhao
}

\begin{abstract}
Apolipoprotein C3 (apoC3) and apolipoprotein A5 (apoA5), encoded by APOA1/C3/A4/A5 gene cluster, are two critical regulators of plasma triglyceride (TG) metabolism. Deficiency of apoC3 or apoA5 led to significant decreased or increased plasma TG levels, respectively. Recent studies indicated apoC3 and apoA5 also played roles in plasma remnant cholesterol, high density lipoprotein (HDL) and hepatic TG metabolisms. Moreover, large scale population genetic studies indicated that loss of function mutations in APOC3 and APOA5 gene conferred decreased and increased risk of coronary artery disease (CAD), respectively. This manuscript mainly reviewed existing evidences suggesting the opposite role of apoC3 and apoA5 in lipid metabolism and CAD risk, and discussed the potential correlation between these two apolipoproteins.
\end{abstract}

Keywords: Apolipoprotein C3, Apolipoprotein A5, Coronary artery disease, Atherosclerosis, Remnant cholesterol

\section{Introduction}

Apolipoprotein C3 (apoC3) and apolipoprotein A5 (apoA5) are encoded by $A P O A 1 / C 3 / A 4 / A 5$ gene clusters. Evidences from genetic, epidemiological studies and basic experiments have consistently demonstrated that apoC3 and apoA5 are critical modulators of plasma triglyceride (TG) metabolism [1, 2]. Deficiency of apoC3 or apoA5 led to significant decreased or increased plasma TG level in human and mice $[1,2]$. In-depth mechanistic studies revealed apoC3 inhibited plasma TG hydrolysis, remnant lipoprotein uptake and promoted hepatic TG secretion, while apoA5 regulated plasma TG metabolisms in a completely opposite manner $[1,2]$. Recent studies further revealed additional role of apoC3 and apoA5 in remnant cholesterol (RC), high density lipoprotein (HDL) and hepatic TG metabolism [1, 2]. Moreover, large scale population genetic studies indicated that loss of function mutations in APOC3 and APOA5 gene conferred

\footnotetext{
* Correspondence: xyzhaosp@sina.com

${ }^{+}$Wen Dai and Ziyu Zhang contributed equally to this work and were listed as co-first authors.

Department of Cardiology, The Second Xiangya Hospital, Central South University, No. 139, Middle Renmin Road, Changsha 410011, China
}

decreased and increased risk of coronary artery disease (CAD) [3-8], respectively. Thus, apoC3 and apoA5 emerge as potential novel targets to reduce cardiovascular risk. This manuscript mainly reviewed the existing evidences suggesting the opposite role of apoC3 and apoA5 in lipid metabolism and CAD risk, and discussed potential correlation between these two apolipoproteins.

\section{Gene structure and expression regulation}

Human $A P O A 1 / C 3 / A 4 / A 5$ gene clusters are located on chromosome 11q23, where $A P O C 3$ gene is approximately $35 \mathrm{kbp}$ upstream from the APOA5 gene locus [9]. Their sequences are evolutionarily conserved $[10,11]$. Human APOC3 gene regulatory regions contain a set of proximal promotor with four elements $(-283 /+24)$ and distal enhancer with six elements $(-890 /-500)$ [9]. Earlier animal and cell culture studies established that $A P O C 3$ enhancer acted as a common regulatory sequence to direct hepatic and intestinal $A P O A 1, A P O C 3$, and $A P O A 4$ gene expression [9]. However, sufficient liver specific $A P O A 5$ gene expression was obtained in vivo with a $26 \mathrm{~kb}$ DNA XhoI-fragment containing only the $A P O A 5$ gene and thus lacking $A P O C 3$ enhancer

(c) The Author(s). 2019 Open Access This article is distributed under the terms of the Creative Commons Attribution 4.0 International License (http://creativecommons.org/licenses/by/4.0/), which permits unrestricted use, distribution, and reproduction in any medium, provided you give appropriate credit to the original author(s) and the source, provide a link to the Creative Commons license, and indicate if changes were made. The Creative Commons Public Domain Dedication waiver (http://creativecommons.org/publicdomain/zero/1.0/) applies to the data made available in this article, unless otherwise stated.
} 
[10]. Gao et al. further confirmed the $A P O C 3$ enhancer didn't affect $A P O A 5$ expression in transgenic mice [12]. Actually, two elements in APOA5 promotor region have been found critical to direct its expression in human hepatic cell lines [13, 14].

Initiation of gene expression is executed by specific binding of transcription factors to gene regulatory elements, and molecules affecting this process can regulate corresponding gene expression. The concrete structure and regulation mechanisms of $A P O C 3$ and $A P O A 5$ gene expression have been reviewed elsewhere [9], and we will focus here on regulators that are shared by $A P O C 3$ and $A P O A 5$. Indeed, several molecules have been implicated in the same direction regulation of $A P O C 3$ and $A P O A 5$ expression, including upregulation with hepatocyte nuclear factor 4- $\alpha$ (HNF4- $\alpha)[15,16]$ and glucose [17, 18], and downregulation with AMP-activated protein kinase [15, 19], insulin [20-22] and tumor necrosis factor- $\alpha$ (TNF- $\alpha$ ) $[23,24]$. Noticeably, these substances, except for TNF- $\alpha$, are all important components directly involved in glucose metabolism, suggesting $A P O C 3$ and $A P O A 5$ dysregulation may contribute to diabetic dyslipidemia. Opposite direction regulation was also found in that peroxisome proliferator-activated receptor- $\alpha$ (PPAR- $\alpha)$ and farnesoid X-activated receptor (FXR) promoted $A P O A 5[13,14]$ while inhibited $A P O C 3$ expression $[25,26]$. In contrast to $A P O A 5$, the human $A P O C 3$ gene promoter doesn't contain PPAR- $\alpha$ and FXR positive response elements. Actually, these two nuclear receptors acted indirectly by interfering the binding of other transcriptional factors, like HNF4- $\alpha$, to specific elements of $A P O C 3$, thereby further inhibiting $A P O C 3$ gene transcription $[26,27]$. Thus, the plasma TG lowering effect of fibrates, one type of PPAR- $\alpha$ agonists, may be partly mediated by increasing the circulating concentration of apoA5 and/or decreasing apoC3 levels. Indeed, recent studies showed that both fenofibrates and omega-3 polyunsaturated fatty acids therapy significantly decreased plasma apoC3 levels in humans $[28,29]$.

\section{Plasma lipid metabolism \\ Lipoprotein distribution}

Circulating apoC3 and apoA5 were mainly associated with triglyceride rich protein (TRL) and HDL $[11,30]$. Studies showed either of apoC3 and apoA5 was exchangeable between TRL and HDL [31]. In normolipidemia state of human subjects, the majority of plasma apoC3 was bound to HDL [32]. On the contrary, in subjects with hypertriglyceridemia (HTG), apoC3 was mostly found on very low density lipoprotein (VLDL) [33]. With the concentration of TG in artificial TG emulsions increasing, a greater fraction of apoC3 shifted away from native plasma lipoproteins to artificial emulsions [33]. Glangeaud et al. [34] found during the lipoprotein lipase (LPL) mediated hydrolysis of VLDL, apoC3 redistributed from VLDL to HDL in vitro study, with the amount that was proportional to the magnitude of TG hydrolysis in VLDL, and apoC3 was subsequently transferred back to newly synthesized TG-enriched VLDL particles [11]. Similarly, Nelbach et al. [35] demonstrated apoA5 was predominantly associated with HDL in APOA5 transgenic mice, which had TG-rare VLDL, but was rapidly and efficiently redistributed to TGrich VLDL isolated from APOA5 knockout mice upon incubation. Shu et al. [36] also reported that intravenous injection of apoA5-containing reconstituted HDL in APOA5 knockout mice showed the identical exchange pattern of apoA 5 between reconstituted HDL and VLDL, and apoA5 still remained associated with the TG-rich VLDL due to the disruption of VLDL hydrolysis.

These findings suggested that lipoprotein distributions of apoC3 and apoA5 were closely associated with the TG contents in TRL. The majority of apoC 3 and apoA5 were in HDL when there was low TG levels in TRL. A large portion of apoC3 and apoA5 redistributed from HDL to TRL particles when TG amounts increased in TRL, and they gradually shuttled back to HDL with the processing of TRL hydrolysis. However, the biologic function and regulation mechanism of the exchange process have not been well elucidated.

\section{Plasma TG}

ApoC3 and apoA5 are critical determinants of plasma TG concentration as evidenced by genetic observations in humans. Loss of function mutations in human APOC3 gene conferred a low plasma TG profile [3-5], while patients with $A P O A 5$ deficiency mutation had extremely high plasma TG levels [37-39]. Abnormalities in apoC3 and apoA5 were associated with different forms of HTG, such as familial hyperchylomicronemia [38, 40], familial combined hyperlipidemia [41-43], and familial dysbetalipoproteniemia [44]. Interestingly, recent studies showed the existence of single glycosylation site at Threonine 74 of apoC3 protein, giving rise to four major proteoforms in plasma. The wild-type form which does not contain a glycan chain is commonly referred to apoC3 $3_{0 \mathrm{a}}$. The rest other three all have a core glycan chain made of an O-linked disaccharide galactose linked to $\mathrm{N}$-acetylgalactosamine. $\mathrm{ApoC}_{0 \mathrm{~b}}$ is the proteoform that just contain the glycan core, while apoC $3_{1}$ and apoC3 $3_{2}$ contain additional one and two sialic acid residues, respectively [45]. Moreover, four major proteoforms of apoC3 differentially correlated to fasting TG levels. It has been found that, using mass spectrometric immunoassay measurement, plasma apoC $3_{0 a}$, apoC $3_{0 b}$, and apoC $3_{1}$ had positive while apoC $3_{2}$ had negative 
relationship with fasting plasma TG [45], suggesting that analysis of individual isoforms of apoC3 could provide more comprehensive information than total plasma apoC3 concentration only.

Consistently, APOC3 knockout mice had decreased TG concentration $(-30 \%)$ compared to wild littermates, while APOC3 transgenic mice showed increased serum TG level (+200\% to $2000 \%)$ [46, 47]. On the other hand, APOA5 knockouts had an increase $(+400 \%)$ in TG levels whereas $A P O A 5$ transgenic mice displayed significantly reduced $(-70 \%)$ in this lipid parameter [48].

In-depth mechanistic studies revealed that apoC3 and apoA5 regulated plasma TG levels through multiple pathways. ApoC3 inhibited LPL mediated TRL hydrolysis, circulating TRL remnant clearance and promoted hepatic TG secretion. Interestingly, apoA5 regulated plasma TG metabolism in a completely opposite manner. Namely, apoA5 accelerated TRL hydrolysis, TRL remnants uptake by liver while inhibited hepatic TG secretion $[1,49]$ (Fig. 1).

\section{Plasma RC}

$\mathrm{RC}$ is defined as the total cholesterol contents of TRL, including VLDL and intermediate-density lipoproteins (IDL) in the fasting state, and VLDL, IDL, and chylomicron remnants in the non-fasting state. Growing evidence indicated that RC is an independent causal risk factor of ischemic heart disease [50,
51]. Moreover, elevated RC levels were associated with increased all-cause mortality in patients with ischemic heart disease [52].

Since apoC3 and apoA5 regulated TRL metabolisms, it is not unexpectedly to find that $A P O C 3$ and $A P O A 5$ gene variants were associated with RC levels. In a metaanalyses of 137,895 individuals, RC was $43 \%$ lower in APOC3 loss-of-function heterozygotes versus noncarriers [53]. Contrarily, genotype combinations of common variants of APOA5 (c.-1131 T > C, S19 W, and c." $31 \mathrm{C}>$ $\mathrm{T})$ associated with increases in RC of up to 56\% [6]. Thus, targeting apoC3 or apoA 5 seems to be a potential approach to reduce plasma $\mathrm{RC}$ levels, which could be testified in future trials.

\section{$H D L$}

HDL exerts various athero-protective properties, including mediating cholesterol efflux, protecting vascular endothelium, anti-inflammatory and anti-apoptotic effects [54]. HDL with deficiencies in these properties is referred to as dysfunctional HDL, which in turn contributes to the progression of CAD. Human observation studies indicated these properties were defective under pathological disorders. For example, impaired cholesterol efflux capacity was found with HDL from uremic patients [55]. Riwanto et al. [56] found HDL from CAD patients didn't activate endothelial anti-apoptotic pathways, but rather stimulates potential endothelial

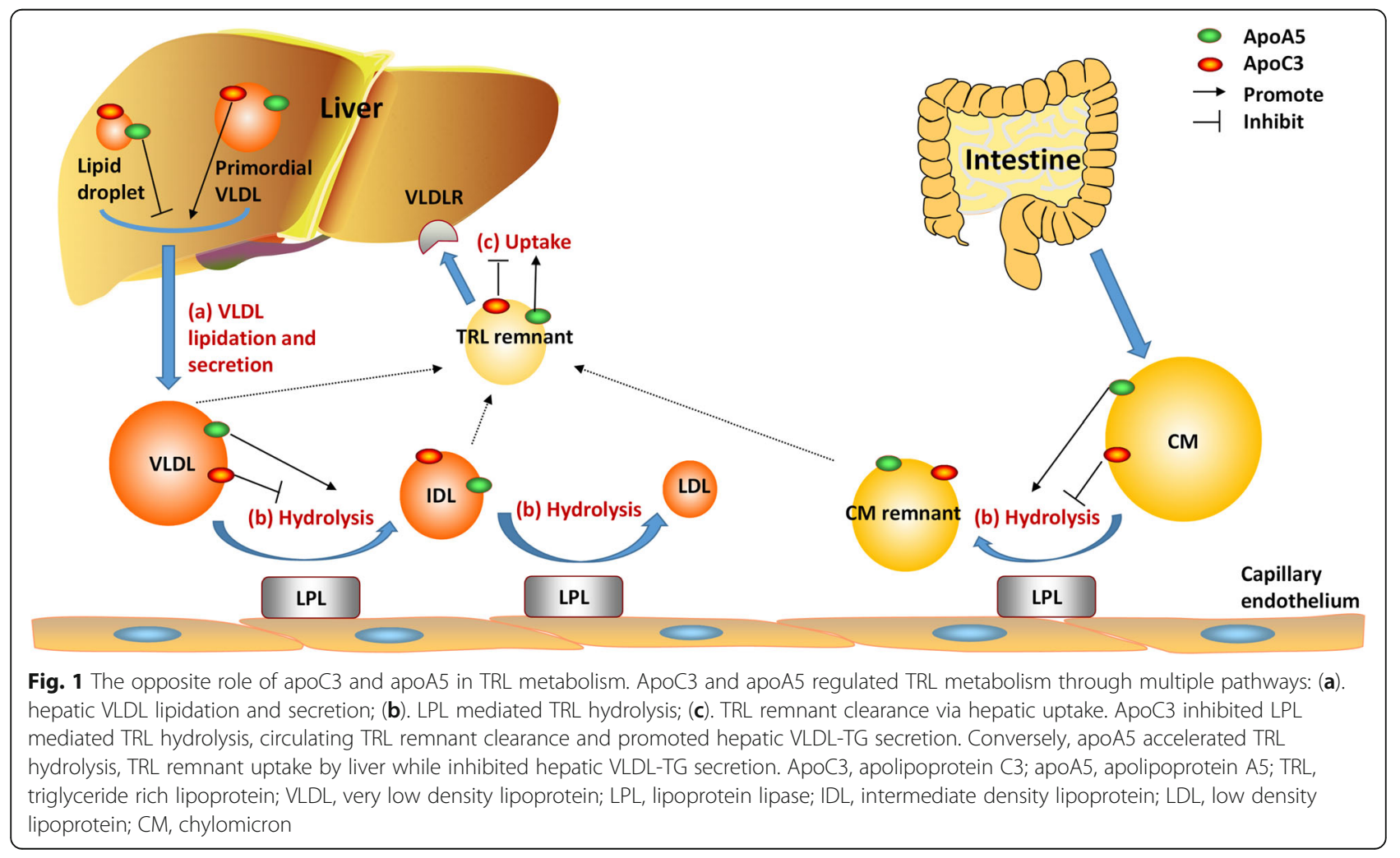


pro-apoptotic pathways. By spectrometry and biochemical analyses, studies further indicated impaired HDL function correlated closely to the alteration in its proteome composition [54, 55, 57], among which changes of apoC3 and apoA5 gained lots of attentions.

Riwanto et al. found that there were significant higher apoC3 in HDL particle from CAD patients compared to healthy controls. Besides, using antibody neutralizing apoC3 in these HDL improved HDL mediated antiendothelial apoptosis function [56]. Cho KH showed increasing apoC3 content in artificial reconstituted HDL reduced its lecithin cholesterol acyltransferase (LCAT) activation ability [58]. Interestingly, Luo $\mathrm{M}$ et al. demonstrated ApoC3 contents in HDL were negatively associated with HDL-mediated cholesterol efflux capacity [59], however, underlying mechanism are unknown. By contrast, adenovirus-mediated overexpression of APOA5 in mice led to increased apoA5 in HDL, associated with increased cholesterol efflux capacity [60]. Reconstituted HDL synthesized with more apoA5 had larger particle size, more lipid content and better antioxidant capacity against LDL in vitro [61].

The definite role of apoC3 and apoA5 in HDL function need to be further examined. It's been reported that apoC3 in HDL can bind to scavenger receptor B1 (SR-B1) [62], with uncharacterized structure domain. SR-B1 is known as an important element in cholesterol reverse transportation partly for facilitating the selectively uptake of cholesterol esters from HDL by the liver [62]. Whether this interaction of apoC3 with SR-B1 would influence cholesterol reverse transportation are undetermined.

\section{Hepatic VLDL secretion}

One of the major functions of the liver is to synthesize and secrete VLDL. VLDL is composed of a core of neutral lipids, mostly TG, and several apolipoproteins [63]. Of which, apolipoprotein B100 (apoB100) is the most important and provides structural stability to the VLDL particle. There are two steps for the biogenesis of VLDL. Initially, the formation of VLDL starts with the synthesis of apoB100 in the endoplasmic reticulum (ER). The nascent apoB100 is then partially lapidated to form a lipidpoor primordial VLDL particle, which is facilitated by microsomal triglyceride transfer protein (MTP). In the second step of VLDL formation, the primordial VLDL particle fuses with triglyceride-rich particles to form mature TG-rich VLDL [63]. Growing evidences have indicated apoC3 and apoA5 regulated the VLDL lipidation and affected the hepatic TG content $[1,49]$ (Fig. 1).

Data from cell culture, animal experiments and human studies confirmed that apoA5 inhibited VLDL-TG secretion and promoted the storage of TG in cytosolic lipid droplet. McA-RH7777 cells stably transfected with human APOA5 secrete VLDLs that were smaller than those from control cells, but had greater cell TG level and larger lipid droplets $[64,65]$. By contrast, Ress et al. [66] reported that knockdown of $A P O A 5$ in HepG2 cells led to a decrease in cellular TG content. Livers from APOA5 transgenic mice had increased hepatic TG level compared with wild littermates [67]. Qin et al. [68] found patients with nonalcoholic fatty liver disease (NAFLD) have elevated $A P O A 5$ expression compared to healthy controls. However, there're still some puzzlements needed to be further elucidated. Primarily, whereby does a portion of apoA5 escape secretion pathway into blood and become associated with cytosolic lipid droplets? Additionally, how does apoA5 promote hepatic TG storage in lipid droplet (LD) instead of secretion in the form of VLDL.

Conversely, in vivo and in vitro studies have shown apoC3 has a stimulatory effect on VLDL lipidation. Feeding $A P O C 3$ knockout mice with a high fat diet for two weeks failed to stimulate VLDL-TG production, while reconstitution of APOC3 expression using adenovirus encoding human apoC3 resulted in robust production of VLDL-TG [69]. The stimulatory effect of human apoC3 on the lipidation of VLDL was recapitulated in McA-RH7777 cells under lipid-rich condition [70]. Furthermore, site directed mutation of residues in lipid binding domain (K58E) of apoC3 abolished this stimulatory effect [69]. These findings were isupported in humans by the observations that two SNPs of $A P O C 3$ (C-482 T, T-455C), leading to decreased APOC3 expression, were correlated with increased hepatic TG level and higher prevalence of NAFLD in Asian indian population [71].

The subcellular location of apoA5 and apoC3 regulating VLDL lipidation are proposed to be the ER compartment. Gao et al. hypothesized that apoA5 may facilitate the ERluminal LDs budding outward to form cytosolic LD and hence reduce the TG assembled into VLDL particles [65]. Qin et al. found apoC3 promoted the fusion of ERluminal LD with VLDL particles during VLDL lipidation [69]. In-depth studies focusing on the molecular basis underlying the effect of apoA5 and apoC3 on VLDL lipidation and LD metabolism are needed, which will provide novel understanding of hepatic TG homeostasis.

\section{Association with CAD}

CAD has become a major cause of death worldwide. Low-density lipoprotein cholesterol (LDL-C) is wellacknowledged as playing a crucial role in the pathogenesis of CAD, and lowering of plasma LDL-C results in significant reduction in the morbidity and mortality of CAD [72, 73]. However, it has been reported that many individuals still suffered CAD despite achieving therapeutic goal for LDL-C levels [74, 75]. Therefore, efforts are on to identify other modifiable risk factors to further 
reduce the risk of CAD. Population genetic data is free of confounding and reverse causation, and is thus recognized as an important way to identify novel potential risk factors of CAD.

Interestingly, it has been demonstrated that genetically reduced plasma apoC3 levels were associated with decreased risk of CAD in humans [3-5]. A nonsense mutation of $A P O C 3$ gene, R19X, was associated with a $50 \%$ reduction of circulating apoC3 levels [5]. More importantly, carriers of the rare variant R19X had lower incidence of coronary artery calcification and lower Framingham 10 year CAD risk [5]. The cardioprotective effect of R19X and other three rare variants, two splice site mutations (IVS2 $+1 \mathrm{G} \rightarrow \mathrm{A}$; IVS3 $+1 \mathrm{G} \rightarrow \mathrm{T}$ ) and one missense mutation (A43T) in APOC3 gene, was recently confirmed in two large-scale studies [3, 4]. In a study as a part of the Exome Sequencing Project of the National Heart, Lung, and Blood Institute [3], approximately 1 in 150 participants was a heterozygous carrier of at least one of these four mutations, and circulating levels of $A P O C 3$ in carriers were $46 \%$ lower than levels in noncarriers. The risk of CAD among 498 carriers of any rare APOC3 mutation was $40 \%$ lower than the risk among 110, 472 noncarriers. Consistently, in a cohort of 75,725 participants, the cumulative incidences of ischemic vascular disease and ischemic heart disease were reduced in heterozygotes for loss-of-function mutations in APOC3 $(\mathrm{R} 19 \mathrm{X}$ or $\mathrm{A} 43 \mathrm{~T}$ or IVS2 $+1 \mathrm{G} \rightarrow \mathrm{A})$ as compared with noncarriers, with corresponding risk reductions of $41 \%$ and $36 \%$ [4]. Noticeably, it has been reported that there was also a trend for fewer major adverse cardiovascular disease events in patients with higher apoC $3_{2}$ proteoform, while these associations were not detected for the other apoC3 proteoforms, suggesting apoC $3_{2}$ is more like a loss-of-function proteoform [45].

Contrarily, APOA5 variants leading to decreased apoA5 levels were associated with increased CAD risk $[6-8,76]$. The association between $-1131 \mathrm{~T}>\mathrm{C}$ promoter polymorphism of APOA5 gene and risk of CAD has been shown in a large meta-analysis. The odds ratio for CAD was 1.18 per $C$ vs. T allele [8]. Furthermore, several independent studies have consistently indicated that $A P O A 5$ variants were significantly associated with the risk of myocardial infarction (MI). Raffaele De Caterina et al. found strong association of the APOA5 -1131 $\mathrm{T}>\mathrm{C}$ gene variant and early-onset acute MI [77]. Jorgensen $\mathrm{AB}$ et al. further showed genetic variation in the APOA5 gene (c.-1131 T. C, S19 W, and c.*31C. T) associated with an $87 \%$ increase in MI risk [6]. Do $\mathrm{R}$ et al. sequenced the exons of APOA5 in 6721 subjects with MI and 6711 controls. 46 unique non-synonymous or splice-site single nucleotide variants or indel frameshifts with allele frequency $<1 \%$ were identified. Moreover, carriers of these rare mutations in APOA5 gene $(1.4 \%$ of cases versus $0.6 \%$ of controls) were at 2.2 -fold increased risk for MI compared to controls [7].

Furthermore, it has been suggested the effects of apoC3 and apoA 5 on CAD risk are partially mediated by changes in plasma RC levels. Wulff $\mathrm{AB}$ et al. found $\mathrm{RC}$ mediated $37 \%$ of the observed $41 \%$ lower risk of ischemic vascular disease and 54\% of the observed 36\% lower risk of ischemic heart disease in $A P O C 3$ loss-of-function heterozygotes versus noncarriers [53]. However, APOA5 gene variants (c.-1131 T. C, S19 W, and c.*31C. T) leading to genetically increased $\mathrm{RC}$ associated with an increased risk of MI [6]. On the other hand, APOA5 gene variants (c.-1131 T. C, S19 W, and c.*31C. T) associated with increases in $\mathrm{RC}$ of up to $56 \%$, and with a corresponding odds ratio for MI of 1.87 [6].

\section{Potential correlation between apoC 3 and apoA5}

Since apoC3 and apoA5 regulate lipid metabolism and associate with CAD risk in an opposite manner, it is reasonable to wonder whether they function independently or cooperately. Some findings from genetic mice suggested a close relationship between these two proteins though there is no current evidence showing the direct interaction between them. Pennacchio et al. [48] demonstrated that $A P O A 5$ transgenic and knockout mice have obviously decreased and increased hepatic apoC3 protein level, respectively, while with no significant changes found in apoC3 mRNA abundance. Indeed, the apoC3 protein amounts in liver were increased $90 \%$ in $A P O A 5$ knockout mice and decreased $40 \%$ in $A P O A 5$ transgenics compared to wild type littermates. Similarly, declined serum apoC3 level was observed after adenovirusmediated overexpression of human APOA5 in mice [60]. These findings implied that apoC3 may affected apoA5 at transcriptional levels, and vice versa. However, the underlying mechanisms are unknown.

\section{Conclusion}

Considerable evidences showed apoC3 and apoA5 played important and opposite roles in lipid metabolism and CAD risk. Targeting apoC3 and apoA5 may be an intriguing therapy for lipid management and cardiovascular protection, which should be testified in future clinical trials.

\footnotetext{
Abbreviations

apoA5: Apolipoprotein A5; apoB100: Apolipoprotein B100; ApoC3: Apolipoprotein C3; CAD: Coronary artery disease; ER: Endoplasmic reticulum; FXR: Farnesoid X-activated receptor; HDL: High density lipoprotein; HNF4-a: Hepatocyte nuclear factor 4-a; HTG: Hypertriglyceridemia; LCAT: Lecithin cholesterol acyltransferase; LD: Lipid droplet; LDL-C: Lowdensity lipoprotein cholesterol; LPL: Lipoprotein lipase; MTP: Microsomal triglyceride transfer protein; NAFLD: Nonalcoholic fatty liver disease; PPARa: Peroxisome proliferator-activated receptor-a; RC: Remnant cholesterol; SRB1: Scavenger receptor B1; TG: Triglyceride; TNF-a: Tumor necrosis factor-a; TRL: Triglyceride rich lipoprotein; VLDL: Very low density lipoprotein
} 


\section{Acknowledgements}

$\mathrm{No}$

\section{Authors' contributions}

Conceived: SPZ. Wrote the paper: WD, ZYZ, CY and SPZ. All authors read and approved the final manuscript.

\section{Funding}

This project was supported by grants from National Natural Science Foundation of China (No. 81170262).

\section{Availability of data and materials \\ Not applicable.}

\section{Ethics approval and consent to participate}

Not applicable.

\section{Consent for publication}

Not applicable.

\section{Competing interests}

The authors declare that they have no competing interests.

Received: 2 June 2019 Accepted: 6 December 2019

Published online: 13 December 2019

\section{References}

1. Norata GD, Tsimikas S, Pirillo A, Catapano AL. Apolipoprotein C-III: From pathophysiology to pharmacology. Trends Pharmacol Sci. 2015;36:675-87.

2. Sharma V, Forte TM, Ryan RO. Influence of apolipoprotein A-V on the metabolic fate of triacylglycerol. Curr Opin Lipidol. 2013;24:153-9.

3. Crosby J, Peloso GM, Auer PL, Crosslin DR, Stitziel NO, Lange LA, et al. Lossof-function mutations in APOC3, triglycerides, and coronary disease. N Engl J Med. 2014;371(1):22-31

4. Jorgensen AB, Frikke-Schmidt R, Nordestgaard BG, Tybjaerg-Hansen A. Lossof-function mutations in APOC3 and risk of ischemic vascular disease. N Engl J Med. 2014:371(1):32-41.

5. Pollin TI, Damcott CM, Shen H, Ott SH, Shelton J, Horenstein RB, et al. A null mutation in human APOC3 confers a favorable plasma lipid profile and apparent cardioprotection. Science. 2008;322(5908):1702-5.

6. Jorgensen AB, Frikke-Schmidt R, West AS, Grande P, Nordestgaard BG, Tybjaerg-Hansen A. Genetically elevated non-fasting triglycerides and calculated remnant cholesterol as causal risk factors for myocardial infarction. Eur Heart J. 2013;34(24):1826-33.

7. Do R, Stitziel NO, Won H-H, Jørgensen AB, Duga S, Angelica Merlini P, et al. Exome sequencing identifies rare LDLR and APOA5 alleles conferring risk for myocardial infarction. Nature. 2014;518(7537):102-6.

8. Triglyceride-mediated pathways and coronary disease: collaborative analysis of 101 studies. The Lancet. 2010;375(9726):1634-9.

9. van Dijk KW, Rensen PCN, Voshol PJ, Havekes LM. The role and mode of action of apolipoproteins CIII and AV: synergistic actors in triglyceride metabolism? Curr Opin Lipidol. 2004;15:239-46.

10. Pennacchio LA, Olivier M, Hubacek JA, Cohen JC, Cox DR, Fruchart JC, et al. An apolipoprotein influencing triglycerides in humans and mice revealed by comparative sequencing. Sci (New York, NY). 2001:294:169-73.

11. Ooi EMM, Barrett PHR, Chan DC, Watts GF. Apolipoprotein C-III: understanding an emerging cardiovascular risk factor. Clin Sci. 2008;114: 611-24

12. Gao J, Wei Y, Huang Y, Liu D, Liu G, Wu M, et al. The expression of intact and mutant human apoAI/CIII/AIV/AV gene cluster in transgenic mice. J Bio Chem. 2005;280:12559-66.

13. Prieur $\mathrm{X}$, Coste $\mathrm{H}$, Rodríguez JC. The human apolipoprotein AV gene is regulated by peroxisome proliferator-activated receptor-a and contains a novel farnesoid X-activated receptor response element. J Biol Chem. 2003; 278:25468-80

14. Vu-Dac N, Gervois P, Jakel H, Nowak M, Bauge E, Dehondt H, et al. Apolipoprotein A5, a crucial determinant of plasma triglyceride levels, is highly responsive to peroxisome proliferator-activated receptor alpha activators. J Biol Chem. 2003;278(20):17982-5.

15. Prieur X, Schaap FG, Coste H, Rodríguez JC. Hepatocyte nuclear factor4alpha regulates the human apolipoprotein AV gene: identification of a novel response element and involvement in the control by peroxisome proliferator-activated receptor-gamma coactivator-1alpha, AMP-activated protein kinase, an. Mol Endocrinol (Baltimore, Md). 2005;19:3107-25.

16. Howell M, Li R, Zhang R, Li Y, Chen W, Chen G. The expression of Apoc3 mRNA is regulated by HNF4alpha and COUP-TFII, but not acute retinoid treatments, in primary rat hepatocytes and hepatoma cells. Mol Cell Biochem. 2014;387(1-2):241-50.

17. Caron S, Verrijken A, Mertens I, Samanez CH, Mautino G, Haas JT, et al. Transcriptional activation of apolipoprotein CIII expression by glucose may contribute to diabetic dyslipidemia. Arterioscler Thromb Vasc Biol. 2011;31:513-9.

18. Nowak M, Helleboid-Chapman A, Jakel H, Moitrot E, Rommens C, Pennacchio LA, et al. Glucose regulates the expression of the Apolipoprotein A5 gene. J Mol Biol. 2008;380:789-98.

19. Leclerc I, Lenzner C, Gourdon L, Vaulont S, Kahn A, Viollet B. Hepatocyte nuclear factor-4alpha involved in type 1 maturity-onset diabetes of the young is a novel target of AMP-activated protein kinase. Diabetes. 2001;50: 1515-21.

20. Chen M, Breslow JL, Li W, Leff T. Transcriptional regulation of the apoC-III gene by insulin in diabetic mice: correlation with changes in plasma triglyceride levels. J Lipid Res. 1994;35:1918-24.

21. Altomonte J, Cong L, Harbaran S, Richter A, Xu J, Meseck M, et al. Foxol mediates insulin action on apoC-III and triglyceride metabolism. J Clin Invest. 2004;114:1493-503.

22. Nowak M, Helleboid-Chapman A, Jakel H, Martin G, Duran-Sandoval D, Staels B, et al. Insulin-mediated Down-regulation of Apolipoprotein A5 gene expression through the phosphatidylinositol 3-kinase pathway: role of upstream stimulatory factor. Mol Cell Biol. 2005;25:1537-48.

23. Nikolaidou-Neokosmidou V, Zannis VI, Kardassis D. Inhibition of hepatocyte nuclear factor 4 transcriptional activity by the nuclear factor kappa B pathway. Biochem J. 2006:398:439-50.

24. Xs H, Zhao SP, Hu M, Bai L, Zhang Q, Zhao W. Decreased apolipoprotein A5 is implicated in insulin resistance-related hypertriglyceridemia in obesity. Atherosclerosis. 2010;210:563-8

25. Staels B, Vu-Dac N, Kosykh VA, Saladin R, Fruchart JC, Dallongeville J, et al. Fibrates downregulate apolipoprotein C-III expression independent of induction of peroxisomal acyl coenzyme a oxidase. A potential mechanism for the hypolipidemic action of fibrates. J Clin Invest. 1995;95:705-12.

26. Claudel T, Inoue Y, Barbier O, Duran-Sandoval D, Kosykh V, Fruchart J, et al. Farnesoid $X$ receptor agonists suppress hepatic apolipoprotein CIII expression. Gastroenterology. 2003;125:544-55.

27. Mode of action of peroxisome proliferators as hypolipidemic drugs. Suppression of apolipoprotein C-III, (1995).

28. Sahebkar A, Simental-Mendia LE, Katsiki N, Reiner Z, Banach M, Pirro M, et al. Effect of fenofibrate on plasma apolipoprotein C-III levels: a systematic review and meta-analysis of randomised placebo-controlled trials. 2019; 8(11):e021508

29. Sahebkar A, Simental-Mendia LE, Mikhailidis DP, Pirro M. Effect of omega-3 supplements on plasma apolipoprotein C-III concentrations: a systematic review and meta-analysis of randomized controlled trials. 2018;50(7):565-75.

30. O'Brien PJ, Alborn WE, Sloan JH, Ulmer M, Boodhoo A, Knierman MD, et al. The novel apolipoprotein a5 is present in human serum, is associated with $\mathrm{VLDL}, \mathrm{HDL}$, and chylomicrons, and circulates at very low concentrations compared with other apolipoproteins. Clin Chem. 2005:51:351-9.

31. Wu CL, Zhao SP, Yu BL. Intracellular role of exchangeable apolipoproteins in energy homeostasis, obesity and non-alcoholic fatty liver disease. Biol Rev Camb Philos Soc. 2015;90(2):367-76.

32. Malmendier CL, Lontie JF, Grutman GA, Delcroix C. Metabolism of apolipoprotein C-III in normolipemic human subjects. Atherosclerosis. 1988; 69:51-9.

33. Tornoci L, Ca S, Li X, ide H, Goldberg IJ, Na L. Abnormal activation of lipoprotein lipase by non-equilibrating apoC-II: further evidence for the presence of non-equilibrating pools of apolipoproteins C-II and C-III in plasma lipoproteins. J Lipid Res. 1993;34:1793-803.

34. Glangeaud MC, Eisenberg S, Olivecrona T. Very low density lipoprotein. Dissociation of apolipoprotein C during lipoprotein lipase induced lipolysis. Biochim Biophys Acta. 1976:486:23-35.

35. Nelbach L, Shu X, Konrad RJ, Ryan RO, Forte TM. Effect of apolipoprotein A$\checkmark$ on plasma triglyceride, lipoprotein size, and composition in genetically engineered mice. J Lipid Res. 2008;49:572-80.

36. Shu X, Nelbach L, Weinstein MM, Burgess BL, Beckstead JA, Young SG, et al. Intravenous injection of Apolipoprotein A-V reconstituted high-density 
lipoprotein decreases hypertriglyceridemia in apoav-/- mice and requires Glycosylphosphatidylinositol-anchored high-density lipoprotein-binding protein 1. Arterioscler Thromb Vasc Biol. 2010;30:2504-9.

37. Oliva CP, Pisciotta L, Li Volti G, Sambataro MP, Cantafora A, Bellocchio A, et al. Inherited apolipoprotein A-V deficiency in severe hypertriglyceridemia. Arterioscler Thromb Vasc Biol. 2005;25:411-7.

38. Marcais C, Verges B, Charriere S, Pruneta V, Merlin M, Billon S, et al. Apoa5 Q139X truncation predisposes to late-onset hyperchylomicronemia due to lipoprotein lipase impairment. J Clin Invest. 2005;115(10):2862-9.

39. Priore Oliva C, Carubbi F, Schaap FG, Bertolini S, Calandra S. Hypertriglyceridaemia and low plasma HDL in a patient with apolipoprotein A-V deficiency due to a novel mutation in the APOA5 gene. J Intern Med. 2008:263(4):450-8.

40. Gaudet D, Brisson D, Tremblay K, Alexander VJ, Singleton W, Hughes SG, et al. Targeting APOC3 in the familial chylomicronemia syndrome. N Engl Med. 2014;371(23):2200-6.

41. Pennacchio LA, Rubin EM. Apolipoprotein A5, a newly identified gene that affects plasma triglyceride levels in humans and mice. Arterioscler Thromb Vasc Biol. 2003;23(4):529-34.

42. Di Taranto MD, Staiano A, D'Agostino MN, D'Angelo A, Bloise E, Morgante A, et al. Association of USF1 and APOA5 polymorphisms with familial combined hyperlipidemia in an Italian population. Mol Cell Probes. 2015;29(1):19-24.

43. Shoulders CC, Jones EL, Naoumova RP. Genetics of familial combined hyperlipidemia and risk of coronary heart disease. Hum Mol Genet. 2004;13 Spec No 1:R149-R160.

44. Henneman P, van der Sman-de Beer F, Moghaddam PH, Huijts P, Stalenhoef AF, Kastelein JJ, et al. The expression of type III hyperlipoproteinemia: involvement of lipolysis genes. Eur J Hum Genet. 2009;17(5):620-8.

45. Nedelkov D. Mass Spectrometric Studies of Apolipoprotein Proteoforms and Their Role in Lipid Metabolism and Type 2 Diabetes. Proteomes. 2017;5(4).

46. Ito Y, Azrolan N, O'Connell A, Walsh A, Breslow JL. Hypertriglyceridemia as a result of human apo CIII gene expression in transgenic mice. Sci (New York, NY). 1990;249:790-3.

47. Maeda N, Li H, Lee D, Oliver P, Quarfordt SH, Osada J. Targeted disruption of the apolipoprotein C-III gene in mice results in hypotriglyceridemia and protection from postprandial hypertriglyceridemia. J Biol Chem. 1994;269: 23610-6.

48. Pennacchio LA, Olivier M, Hubacek JA, Cohen JC, Cox DR, Fruchart JC, et al. An apolipoprotein influencing triglycerides in humans and mice revealed by comparative sequencing. Science. 2001;294(5540):169-73.

49. Zheng XY, Zhao SP, Yan H. The role of apolipoprotein $A 5$ in obesity and the metabolic syndrome. Biol Rev. 2013;88:490-8.

50. Varbo A, Benn M, Tybjaerg-Hansen A, Jorgensen AB, Frikke-Schmidt $R$, Nordestgaard BG. Remnant cholesterol as a causal risk factor for ischemic heart disease. J Am Coll Cardiol. 2013;61(4):427-36.

51. Xiang QY, Tian F, Lin QZ, Du X, Zhang SL, Gui YJ, et al. Comparison of remnant cholesterol levels estimated by calculated and measured LDL-C levels in Chinese patients with coronary heart disease. Clin Chim Acta. 2019.

52. Jepsen AM, Langsted A, Varbo A, Bang LE, Kamstrup PR, Nordestgaard BG. Increased remnant cholesterol explains part of residual risk of all-cause mortality in 5414 patients with ischemic heart disease. Clin Chem. 2016; 62(4):593-604

53. Wulff AB, Nordestgaard BG, Tybjaerg-Hansen A. APOC3 loss-of-function mutations, remnant cholesterol, low-density lipoprotein cholesterol, and cardiovascular risk: mediation- and meta-analyses of 137895 individuals. Arterioscler Thromb Vasc Biol. 2018;38(3):660-8.

54. Rosenson RS, Brewer HB, Ansell B, Barter P, Chapman MJ, Heinecke JW, et al. Translation of high-density lipoprotein function into clinical practice: current prospects and future challenges. Circulation. 2013;128:1256-67.

55. Holzer M, Birner-Gruenberger R, Stojakovic T, El-Gamal D, Binder V, Wadsack C, et al. Uremia alters HDL composition and function. JASN. 2011;22:1631-41.

56. Riwanto M, Rohrer L, Roschitzki B, Besler C, Mocharla P, Mueller M, et al. Altered activation of endothelial anti-and proapoptotic pathways by highdensity lipoprotein from patients with coronary artery disease: role of highdensity lipoprotein-proteome remodeling. Circulation. 2013;127:891-904.

57. Talayero B, Wang L, Furtado J, Carey VJ, Bray GA, Sacks FM. Obesity favors apolipoprotein $\mathrm{E}$ - and $\mathrm{C}$-III-containing high density lipoprotein subfractions associated with risk of heart disease. J Lipid Res. 2014;55:2167-77.

58. Cho KH. Synthesis of reconstituted high density lipoprotein ( $\mathrm{rHDL}$ ) containing apoA-I and apoC-III: the functional role of apoC-III in rHDL. Mo Cells. 2009;27:291-7.
59. Luo M, Liu A, Wang S, Wang T, Hu D, Wu S, et al. ApoClll enrichment in HDL impairs HDL-mediated cholesterol efflux capacity. Sci Rep. 2017:7(1):2312

60. Qu S, Perdomo G, Su D, D'Souza FM, Shachter NS, Dong HH. Effects of apoA-V on HDL and VLDL metabolism in APOC3 transgenic mice. J Lipid Res. 2007:48(7):1476-87.

61. Zhang $X$, Wang J, Chen B. Effect in vitro of apolipoprotein A-V on the structure and functions of recombinant high density lipoprotein. Biochem Biophys Res Commun. 2010;401:473-9.

62. Xu S, Laccotripe M, Huang X, Rigotti a, Zannis VI, Krieger M. Apolipoproteins of $\mathrm{HDL}$ can directly mediate binding to the scavenger receptor SR-BI, an HDL receptor that mediates selective lipid uptake. J Lipid Res. 1997;38:1289-98.

63. Tiwari S, Siddiqi SA. Intracellular trafficking and secretion of VLDL. Arterioscler Thromb Vasc Biol. 2012;32(5):1079-86.

64. Blade AM, Ma F, Hou L, Weinberg RB, Shelness GS. Biogenesis of apolipoprotein A-V and its impact on VLDL triglyceride secretion. J Lipid Res. 2011;52:237-44

65. Gao X, Forte TM, Ryan RO. Influence of apolipoprotein A-V on hepatocyte lipid droplet formation. Biochem Biophys Res Commun. 2012;427:361-5.

66. Ress C, Moschen aR, Sausgruber N, Tschoner a, Graziadei I, Weiss H, et al. The role of apolipoprotein A5 in non-alcoholic fatty liver disease. Gut. 2011; 60:985-91.

67. Shu X, Nelbach L, Ryan RO, Forte TM. Apolipoprotein A-V associates with intrahepatic lipid droplets and influences triglyceride accumulation. Biochimica et Biophysica Acta (BBA) - Molecular and Cell Biology of Lipids. 2010;1801:605-8.

68. Feng Q, Baker SS, Liu W, Arbizu RA, Aljomah G, Khatib M, et al. Increased apolipoprotein A5 expression in human and rat non-alcoholic fatty livers. Pathology. 2015;47:341-8.

69. Qin W, Sundaram M, Wang Y, Zhou H, Zhong S, Chang CC, et al. Missense mutation in APOC3 within the C-terminal lipid binding domain of human ApoC-III results in impaired assembly and secretion of triacylglycerol-rich very low density lipoproteins: evidence that ApoC-III plays a major role in the formation of lipid precursors within the microsomal lumen. J Biol Chem 2011;286(31):27769-80

70. Sundaram M, Zhong S, Bou Khalil M, Links PH, Zhao Y, lqbal J, et al. Expression of apolipoprotein C-III in MCA-RH7777 cells enhances VLDL assembly and secretion under lipid-rich conditions. J Lipid Res. 2010;51:150-61.

71. Petersen KF, Dufour S, Hariri a, Nelson-Williams C, foo JN, Zhang X-m, et al. Apolipoprotein C3 gene variants in nonalcoholic fatty liver disease. N Engl J Med. 2010;362:1082-9.

72. Jacobson TA, Ito MK, Maki KC, Orringer CE, Bays HE, Jones PH, et al. National Lipid Association recommendations for patient-centered management of dyslipidemia: part 1 - executive summary. J Clin Lipidol. 2014;8(5):473-88.

73. Ridker PM. LDL cholesterol: controversies and future therapeutic directions. Lancet. 2014;384(9943):607-17.

74. Efficacy and safety of more intensive lowering of LDL cholesterol: a metaanalysis of data from 170000 participants in 26 randomised trials. The Lancet. 2010;376(9753):1670-81.

75. Farnier M. Future lipid-altering therapeutic options targeting residual cardiovascular risk. Curr Cardiol Rep. 2016;18(7):65.

76. Reiner Z. Hypertriglyceridaemia and risk of coronary artery disease. Nat Rev Cardiol. 2017;14(7):401-11.

77. De Caterina R, Talmud PJ, Merlini PA, Foco L, Pastorino R, Altshuler D, et al. Strong association of the APOA5-1131T>C gene variant and early-onset acute myocardial infarction. Atherosclerosis. 2011;214(2):397-403.

\section{Publisher's Note}

Springer Nature remains neutral with regard to jurisdictional claims in published maps and institutional affiliations. 